\title{
İçme Suyu Kaynaklarındaki Trihalometan Oluşumunun İncelenmesi
}

\author{
Nizamettin Özdoğan ${ }^{1 *}$, Kadir Özdemir ${ }^{2}$ \\ ${ }^{1}$ Zonguldak Bülent Ecevit Üniversitesi, Mühendislik Fakültesi, Çevre Mühendisliği Bölümü, Zonguldak, Türkiye (ORCID: 0000-0001-5520-5124) \\ ${ }^{2}$ Zonguldak Bülent Ecevit Üniversitesi, Mühendislik Fakültesi, Çevre Mühendisliği Bölümü, Zonguldak, Türkiye (ORCID: 0000-0003-1464-7078)
}

(İlk Geliş Tarihi 22 Ekim 2019 ve Kabul Tarihi 15 Kasım 2019)

(DOI: 10.31590/ejosat.635926)

ATIF/REFERENCE: Özdoğan, N. \& Özdemir, K. (2019). İçme Suyu Kaynaklarındaki Trihalometan Oluşumunun İncelenmesi. Avrupa Bilim ve Teknoloji Dergisi, (17), 776-785.

\section{Öz}

İçme suyu kaynakları doğal organik maddeler (DOM) içermektedir. Suda bulunan bu organik maddelerin dezenfeksiyon sürecinde klorla reaksiyona girmesi sonucu Trihalometan (THM) olarak adlandırılan klorlu yan ürünler oluşmaktadır. THM'lar kanserojen etkiye sahip bileşikler olmasından dolayı insan ve çevre sağlığı açısından son derece sakıncalıdır. Bu çalışmada, doğal organik madde içeren içme suyu kaynaklarının klorlanması sonucu meydana gelen toplam trihalometan oluşum potansiyeli (THMOP) ve trihalometan (THM) bileşiklerinin dağılımına etki eden başlıca faktörler incelenmiştir. Çalışma alanı ve içme suyu kaynağı olarak Terkos Gölü (İstanbul), Büyükçekmece Gölü (İstanbul), Ulutan Barajı (Zonguldak) seçilmiş̧ir. Alınan ham su örneklerinde, doğal organik madde miktarı, Toplam Organik Karbon (TOK), 254 nm'de UV absorban $\left(\mathrm{UV}_{254}\right)$ ve spesifik UV absorban (SUVA) parametrelerinin analizleri laboratuvar ortamında gerçekleştirilmiş̧ir. En yüksek SUVA değerine sahip Terkos gölü ham sularında bulunan DOM'lerin organik karbonu, hidrofobik özellik gösteren fraksiyonlu bileşiklerden meydana gelirken, daha düşük değere sahip Büyükçekmece gölü ve Ulutan Barajı ham sularında bulunan DOM'in ise daha çok hidrofilik özellik gösteren organiklerden meydana geldiği tespit edilmiştir. Diğer yandan söz konusu içme suyu kaynaklarından alınan ham su örnekleri belirli $\mathrm{Cl}_{2}$ /TOK oranlarına göre klorlanarak 2-168 saatlik reaksiyon süresine maruz bırakılmış ve sonunda meydana gelen THM miktarlarının analizleri EPA-551.1 metodunda yer alan sıvı-sıvı ekstraksiyon yöntemine göre gerçekleştirilmiştir. En yüksek THM konsantrasyonları (en yüksek SUVA değerine sahip organik karbonu hidrofobik yapıda olan) Terkos ham sularının klorlanması sonucu elde edilmiştir. Bu çalışmada ayrıca farklı pH, klor dozu ve reaksiyon süresinin klorlama sırasında meydana getirdiği THM ve THM türlerinin dağılımı üzerindeki etkileri de gösterilmiştir. Özellikle alkali pH'larda daha yüksek THM oluşumları tespit edilmiş olup, aynı şekilde daha yüksek klor dozlarında ve bekletme sürelerinde daha yüksek THM oluşumlarının gözlenmesi bu çalışmanın elde edilen önemli sonuçlarından biri olmuştur.

Anahtar Kelimeler: Trihalometanlar, Klorlama, İçme suyu kaynakları, Doğal organik madde

\section{Investigation of Trihalomethane Formation in Drinking Water Resources}

\begin{abstract}
Drinking water sources contain natural organic materials (NOM). The reaction of these organic substances with chlorine during disinfection process produces chlorinated by-products called trihalomethane (THM). THM's are extremely dangerous for human and environmental health because they are carcinogenic compounds. In this study, we investigated the potential of total formation of Trihalometan (THM) due to chlorination of drinking water resources with natural organic matters (NOM), and the main factors affecting the distribution of Trihalomethane (THM) compounds. Terkos Lake (Istanbul), Büyükçekmece Lake (Istanbul) and Ulutan Dam
\end{abstract}

\footnotetext{
*Sorumlu Yazar: Zonguldak Bülent Ecevit Üniversitesi, Mühendislik Fakültesi, Çevre Mühendisliği Bölümü, Zonguldak, Türkiye, ORCID: 00000001-5520-5124, nozdogan@,beun.edu.tr
} 


\section{European Journal of Science and Technology}

(Zonguldak) were selected as the study area and drinking water source. Along with parameters of Total Organic Carbon(TOC), analysis of UV absorbed ( $\mathrm{UV}_{254}$ ) and specific UV absorbance (SUVA) parameters at $254 \mathrm{~nm}$, the amount and analysis of natural organic matter in raw water samples were carried out in laboratory. In the raw waters of Terkos Lake, which has the highest SUVA value, the DOM was found to be mostly composed of organics with hydrophilic properties. On the other hand, raw water samples taken from these drinking water sources were chlorinated according to certain $\mathrm{Cl}_{2} / \mathrm{TOC}$ ratios and subjected to a reaction time of 2-168 hours. The evaluation of output of this reaction as the THM amounts were carried out according to the liquid-liquid extraction method of EPA551.1 method. The highest THM concentrations were obtained by chlorination of Terkos raw waters (hydrophobic organic carbon with the highest SUVA value). In this study, the effects of different PH, chlorine dose and reaction time on the distribution of THM and THM species produced during chlorination were also shown. In particular, higher THM formations were detected at alkaline $\mathrm{pH}$, and higher THM formations at higher chlorine doses and retention times were one of the important results of this study.

Keywords: Trihalomethanes, Chlorination, Drinking water resources, Natural organic matter

\section{Giriș}

Su ortamında bulunan doğal organik maddeler, bitki ve hayvan atıklarının mikrobiyal reaksiyonları sonucu çeşitli organik bileşiklerden meydana gelen karmaşık yapılardır (Croue, 2004;Gang, 2001). DOM'nin içeriğini oluşturan organik yapılar yağmur, sel, kar ve kuraklık gibi mevsimsel faktörlere bağlı olarak farklılık gösterebilmektedirler. Bu etmenler DOM'nin yapısı ile beraber su temini ve kalitesinde önemli değişikliklere yol açmaktadırlar (Hwang ve ark, 2000; Barret ve ark, 2000; Summers \& Roberts, 1988; Lei \& Wania, 2004; Sharp ve ark, 2006). İçme suyu kaynaklarında bulunan DOM'in karakterizasyonu; Çözünmüş Organik Karbon (ÇOK), $254 \mathrm{~nm}$ dalga boyundaki UV absorbans ( $\mathrm{UV}_{254}$ ) ve DOM'in hidrofobikliğinin bir göstergesi olan Spesifik UV Absorbans (SUVA) gibi DOM'yi temsil eden organik parametrelere göre gerçekleşmektedir (Sharp ve ark, 2006; Jacangelo ve ark, 1995; Kitis ve ark, 2001). Özellikle DOM içeren yüzeysel sularda yüksek SUVA değerleri (SUVA > 3), DOM'nin içeriğinin daha çok fenol ve karboksil gibi aktif fonksiyonel gruplara sahip yüksek moleküler ağırlıktaki hidrofobik organiklerden meydana geldiğini gösterir. Düşük SUVA değerleri (SUVA $<3$ ) ise alifatik organikler, karboksilik asit ve aminoasitler gibi hidrofilik yapıların daha yüksek oranda bulunduğunu göstermektedir (Kitis ve ark, 2002; Her ve ark, 2008; Lefebvre ve ark, 2006; Owen ve ark, 1995; Vilge ve ark, 1999; Edzwald ve ark, 1985). Diğer yandan yüzeysel su kaynaklarında bulunan DOM, tat, koku, renk ve bakteriyel üreme gibi problemlere neden olmaktadır. Ayrıca, DOM içeren sularda bulunan patojen mikroorganizmaların giderilmesi için yapılan klorlama işlemi sonucunda (denklem 1), insan sağlı̆̆ını olumsuz etkileyen trihalometanlar (THM) ve haloasetik asit (HAA) gibi dezenfeksiyon yan ürünleri (DYÜ) meydana gelmektedir (Bellar ve ark, 1974; Elshorbagy ve ark, 2000; Rook, 1974; Rodriguez \& Serodes, 2001; Uyak ve ark, 2005; Sadiq \& Rodriguez, 2004).

$$
\mathrm{DOM}+\text { Klorlama } \longrightarrow \text { THM+HAA }
$$

Bu konu ile ilgili yapılan çalışmalarda, bu klorlu yan ürünlerin insanlarda kanser, böbrek yetmezliği, bilinç kaybı ve kardiyolojik hastalıklara neden olduğu ortaya koymuştur (Ivancev ve ark, 2002; Dodds ve ark, 1999; Cedergren ve ark, 2002; Yang ve ark, 2000). DYÜ'nin insan sağlığı üzerindeki olumsuz etkilerinden dolayı birçok ülkede içme suyu kalite standartları gözden geçirilerek oluşan yan ürünler için yeni kısıtlamalar getirilmiştir. Amerika Birleşik Devletleri Çevre koruma Örgütü (USEPA) tarafından, HAA ve 4 adet THM türü (Kloroform, bromodiklorometan, dibromoklorometan, ve bromoform) için maksimum kirletici konsantrasyonu sirası ile 60 ve 80 $\mu \mathrm{g} / \mathrm{L}$ olarak belirlenmiştir [Pontius, 1993; USEPA, 2003a; USEPA, 2003b). Bunun yanında aynı klorlu yan ürünler için limit değer Avrupa Birliği (EC) içme suyu standartlarında tarafından $100 \mu \mathrm{g} / \mathrm{L}$ olarak uygulanmaktadır (EC, 1998). Ülkemizde de TSE-266 içme kalite standartlarında THM limit değeri $100 \mu \mathrm{g} / \mathrm{L}$ 'dir (TSE-266, 2012).

Yüzeysel sularda DOM'nin hidrofobik ve hidrofilik fraksiyonlarının temsilinde kullanılan SUVA ve ÇOK gibi organik parametrelerin yanında diğer en önemli gösterge Dezenfeksiyon Yan Ürünü Oluşum Potansiyelinin (DYÜOP) tespit edilmesidir. Başka bir deyişle, klorlama sonucu oluşan en önemli temel DYÜ bileşeni THM olduğundan klorlu bir ham suda THMOP ölçülmesi su kalitesi açısından oldukça önemlidir (Elshorbagy ve ark, 2000; Croue ve ark, 2000). DOM içeren bir içme suyu kaynağının THMOP, normal koşullar altında yüksek klor dozlarında klorlanan su örneklerinde $25^{\circ} \mathrm{C}$ de 7 gün bekletildikten sonra ölçülen THM konsantrasyonudur [Ozdemir ve ark, 2013]. Diğer yandan mevsimsel olarak su içerisindeki DOM içeriğinin değişimi klorlanan bir su numunesinde meydana gelecek olan THM miktarını da önemli ölçüde etkilemektedir. Dolayısıyla içme suyu kaynağının TOK konsantrasyonu, $\mathrm{UV}_{254}$, SUVA, bromür konsatrasyonu ve $\mathrm{pH}$ seviyeleri korlama sırasında oluşacak olan kloroform (KFM), dibromoklorometan (DBKFM), bromodiklorometan (BDKFM) ve bromoform (BFM) gibi THM bileşenlerinin miktarlarını etkileyen önemli faktörlerdir. Bu çalışmada, DOM içeren içme suyu kaynaklarının klorlanması sonucu meydana gelen THM konsantrasyonları ve THM miktarlarının dağılımı üzerinde etkili olan faktörler araştırılmıştır. Deneysel çalışmalar için gerekli ham su numuneleri, sırasıyla, İstanbul şehrine içme suyu tedariki için günde ortalama 2 milyon $\mathrm{m}^{3}$ su temini sağlayan Terkos ve Büyükçekmece gölleri ile Zonguldak iline $34 \mathrm{bin}^{3}$ su sağlayan Ulutan Baraj suyundan alınmıştır. Bu çalışmayı özgün kılan en önemli özelliklerden biri İstanbul'un yanı sıra ilk defa Batı Karadeniz bölgesinde (Zonguldak-Ulutan Barajı) THM oluşumu ve analiziyle ilgili gerçekleştirilmiş bir çalışma olmasıdır. 


\section{Materyal ve Metot}

\subsection{Su numunelerinin toplanması}

Bu çalışmada, ham su kaynağı İstanbul ili Büyükçekmece Gölü, Terkos Gölü ve Zonguldak ili Ulutan Barajı seçilmiştir. Söz konusu ham sulardan numune alma işlemleri Yer Üstü Suları, Yer Altı Suları ve Sedimentten Numune Alma ve Biyolojik Örnekleme Tebliği Yönetmeliği'ne uygun olarak sırasıyla Terkos ham suları için Kağıthane içme suyu arıtma tesisleri, Büyükçekmece ham suları için Büyükçekmece içme suyu arıtma tesisleri ve Ulutan Barajı ham suları için Ulutan Barajı içme suyu arıtma tesislerinden alınmıştır. Her üç tesiste de ham su numuneleri, yaklaşık $4 \mathrm{~m}$ derinliğinde dikdörtgen biçiminde iki kapaklı bir ham su giriş sistemi ile kaba 1zgaralar ve $5 \mathrm{~mm}$ çapındaki eleklerin bulunduğu bölümlerin çıkışlarından tekil numune olarak 20 L'lik plastik numune kaplarına alınmıştır.

Tekil numune olarak toplanan ham su örnekleriyle ilgili su kalite analizleri Zonguldak Bülent Ecevit Üniversitesi Merkez Laboratuvarında yapılmıştır. Alınan ham su numuneleri membran filtrelerden $(0.45 \mu \mathrm{m})$ geçirilerek herhangi bir mikrobiyal aktivitiye maruz kalmaması için deneysel çalışma süresince $+4{ }^{\circ} \mathrm{C}$ 'de buzdolabında muhafaza edilmiştir. Çizelge 1 'de Terkos, Büyükçekmece ve Ulutan barajı ham su örneklerine ait su kalite parametre değerleri verilmiştir. Terkos ve Büyükçekmece gölü ham su numunelerinde tespit edilen değerler literatürle benzerlik göstermiştir (Uyak ve ark, 2008).

Çizelge 1. Terkos ve Büyükçekmece Gölü ile Ulutan Barajı ham suları su kalite parametre değerleri

\begin{tabular}{lllll}
\hline Parametre & \multirow{2}{*}{ Birim } & $\begin{array}{l}\text { Terkos } \\
\text { Ham su }\end{array}$ & $\begin{array}{l}\text { Büyükçekmece } \\
\text { Ham su }\end{array}$ & $\begin{array}{l}\text { Ulutan Barajı } \\
\text { Ham su }\end{array}$ \\
\hline $\mathrm{pH}$ & & $*$ Ort. ${ }^{*}$ Std & Ort. $^{* *}$ Std & Ort. $^{* *}$ Std \\
\hline Bulanıklik & - & $7.85 \pm 0.16$ & $8.05 \pm 0.14$ & $7.21 \pm 0.13$ \\
İletkenlik & $\mathrm{NTU}$ & $4.40 \pm 0.45$ & $5.62 \pm 0.32$ & $3.20 \pm 0.37$ \\
Toplam sertlik & $\mu \mathrm{S} / \mathrm{cm}$ & $432 \pm 14.81$ & $513 \pm 15.87$ & $336 \pm 13.2$ \\
Alkalinite & $\mathrm{mgCaCO}_{3} / \mathrm{L}$ & $126 \pm 7.24$ & $166 \pm 8.34$ & $89 \pm 6.52$ \\
Sicaklik & $\mathrm{mgCaCO}_{3} / \mathrm{L}$ & $105 \pm 6.36$ & $143 \pm 8.02$ & $73 \pm 6.74$ \\
Br & ${ }^{0} \mathrm{C}$ & $13.0 \pm 2.4$ & $10.0 \pm 2.11$ & $14 \pm 2.33$ \\
TOK & $\mathrm{mg} / \mathrm{L}$ & $0.09 \pm 0.02$ & $0.14 \pm 0.02$ & $0.06 \pm 0.01$ \\
UV & $\mathrm{mg} / \mathrm{L}$ & $4.81 \pm 0.27$ & $4.05 \pm 0.24$ & $3.75 \pm 0.21$ \\
SUVA & $\mathrm{cm}{ }^{-1}$ & $0.15 \pm 0.01$ & $0.10 \pm 0.008$ & $0.08 \pm 0.007$ \\
THMOP & $\mathrm{L} / \mathrm{mg} . \mathrm{m}$ & $3.12 \pm 0.014$ & $2.47 \pm 0.01$ & $2.13 \pm 0.008$ \\
\hline
\end{tabular}

*Ort: Ortalama değer

**Std: Standard sapma

\subsection{Klorlama metodu}

Terkos, Büyükçekmece ve Ulutan Barajı ham su örnekleri membran filtreden $(0.45 \mu \mathrm{m})$ geçirildikten sonra fosfat tampon çözeltisiyle pH yediye (7) ayarlanmıştır. Klorlama sürecinde, $5 \mathrm{mg} / \mathrm{mL}$ 'lik stok sodyum hipoklorit (NaOCl) çözeltisi Standart Metodlar 5710 B'ye göre hazırlanmış ve farklı konsantrasyonlardaki klor $100 \mathrm{~mL}$ 'lik viallere aktarılmıştır. $20^{\circ} \mathrm{C}$ 'de karanlık bir ortamda THM oluşumunu tespit etmek için 2, 4, 6, 12, 24, 48, 96 ve 168 saat reaksiyon süresinde bekletilmiştir. Diğer yandan klorlu numunelerde pH etkisini gözlemlemek için su numunelerinin klorlamadan önce $\mathrm{pH}$ değerleri $0.1 \mathrm{~N} \mathrm{HCl}$ ve NaOH olarak hazırlanmış stok çözeltilerden belirli miktarlar kullanılarak $\mathrm{pH}=4,5,6,7,8$ ve 9 olarak ayarlanmıştır. İnkübasyon süresinin sonunda bakiye kloru belirlemek için hazırlanan N,N-dietil-P-fenilindiamin (DPD) ve fosfat tampon çözeltisi numunelere ilave edilmiş ve demir amonyun sülfat çözeltisiyle titrasyon sağlanmıştır (Standart Metotlar 4500-F).

\subsection{THMOP metodu}

THMOP deneyleri Standard Metodlar 5710 B'e göre gerçekleştirilmiştir. Bu deneyin amacı, içme suyu kaynaklarında oluşabilecek maksimum THM konsantrasyonunu tespit etmektir. Bu çerçevede, klorlama işleminden önce fosfat tamponuyla (2.5 mL) $\mathrm{pH} 7$ 'e ayarlanan su numunelerine, $\mathrm{Cl}_{2} / \mathrm{TOK}$ oranı 3.0 olacak şekilde klor ilavesi yapılmış ve $25^{\circ} \mathrm{C}$ 'de 7 gün inkubasyona bırakılmıştır. Klorlama işlemi $100 \mathrm{~mL}$ 'lik teflon kapaklı cam viallerde gerçekleştirilmiştir. 7 günlük periyodun sonunda numunelerdeki bakiye klor miktarları ölçülerek numuneler THMOP ölçümü yapılmak üzere $+4^{\circ} \mathrm{C}$ de buzdolabında saklanmıştır.

\subsection{Analiz Metodları}

Terkos, Büyükçekmece ve Ulutan Barajından alınan su numunelerinde bulunan çözünmüşs organik karbonu (ÇOK) ölçmek için Standart Metotlarda belirtilen 5310 B numaralı yakma (yüksek sıcaklıkta) metodu kullanılmıştır (SM, 2005). ÇOK analizleri Shimadzu TOC 
5000-A Analiz cihazı kullanılarak yapılmıştır. $\mathrm{Bu}$ deneyin amacı, su numunelerinde bulunan organik karbonun yakılarak $\mathrm{CO}_{2}$ gazına dönüştürülmesi ve bu gazın nondispersif infrared analizörü ile ölçülmesi esasına dayanmaktadır.

$\mathrm{UV}_{254}$ absorbans değeri suyun içerisinde bulunan aromatik kromoforların derişimini gösteren bir parametredir. Su numunelerinin $\mathrm{UV}_{254}$ absorban ölçümleri, 1 cm'lik quartz küvetler kullanılarak 254 nm'de Standart Metotlar 5910 B'de belirtilen esaslara göre Shimadzu $1608 \mathrm{UV} /$ Vis spektrofotometre kullanılarak gerçekleştirilmiş̧î (SM, 2005). Ölçümler sırasında su numunelerinde girişime neden olabilecek safsızlıkları (nitrat, nitrit, demir ve bromür gibi) ortadan kaldırmak için $0.45 \mu \mathrm{m}$ membran filtre kullanılmışır.

$\mathrm{Su}$ numunelerinde ölçülen SUVA değeri, $\mathrm{UV}_{254}$ absorban değerinin TOK değerine bölünmesi ile hesaplanır. SUVA değerinin matematiksel hesaplaması aşağıda verilmiştir.

$\operatorname{SUVA}(\mathrm{L} / \mathrm{mg} \cdot \mathrm{m})=100 *\left[\mathrm{UV}_{254}\left(\mathrm{~cm}^{-1}\right) / \mathrm{TOK}(\mathrm{mg} / \mathrm{L})\right]$

THM analizleri $\left(\mathrm{CHCl}_{3}, \mathrm{CHCl}_{2} \mathrm{Br}, \mathrm{CHBr}_{2} \mathrm{Cl}\right.$ ve $\mathrm{CHBr}$ ) $\mathrm{EPA}$ metot 551.1 sıv1-sıv1 ekstraksiyon yöntemine göre Hawlett Packard (HP) marka 7890 model gaz kromatograf (GC)/ ECD cihazı kullanılarak yapılmıştır. Mikro elektron yakalayıcı detektöre ( $\mu$ ECD) sahip GC'ye enjekte edilen klorlu örnekler kapiler kolona (DB-1, 30m*0.32mm I.D.*1.0 $\mu \mathrm{m}$ ) helyum gazı kullanılarak taşınımları gerçekleştirilmiştir. Bu metodun minimum tayin limiti $0.1 \mu \mathrm{g} / \mathrm{L}$ 'dir. Kalibrasyon standartları AGILENT marka THM standardı (lot no: 50429ME, ABD) kullanılarak hazırlanmıştır. Kalibrasyon standartları aralı̆g 10-100 $\mu \mathrm{g} / \mathrm{L}$ arasında olup klorlu su numunelerinin THM konsantrasyonları, kalibrasyon eğrileri kullanılarak hesaplanmıştı. Bromür konsantrasyonları analizi ise EPA Method 300.0 inorganik anyonların tayini için kullanılan iyon kromotografi yöntemine göre ICS-3000 iyon kromotografi cihazı ile gerçekleştirilmiş̧ir.

\section{Araştırma Sonuçları ve Tartışma}

Tablo 1'de Terkos, Ömerli ve Ulutan Barajı ham su kalite parametreleri ile birlikte her bir içme suyu kaynağında bulunan DOM'in karakterize edilmesini sağlayan TOK, $\mathrm{UV}_{254}$ ve SUVA parametrelerinin değerleri verilmiştir. Bu sonuçlara göre DOM'nin yapısını oluşturan aromatik ve aromatik olmayan organik moleküllerin derişimini gösteren TOK değerleri Terkos ve Büyükçekmece Gölü ile Ulutan Barajı su örneklerinde sırası ile; $4.85 \mathrm{mg} / \mathrm{L}, 4.05 \mathrm{mg} / \mathrm{L}$ ve $3.75 \mathrm{mg} / \mathrm{L}$ olarak bulunmuştur. DOM içinde sadece UV absorplayan aromatik kromoforların konsantrasyonunu gösteren $U^{254}$ değeri Terkos Gölü ham sularında $0.15 \mathrm{~cm}^{-1}$ gözlenirken, Büyükçekmece Gölü ham su örneklerinde $0.10 \mathrm{~cm}^{-1}$ ve Ulutan Barajı ham su örneklerinde ise $0.08 \mathrm{~cm}^{-1}$ olduğu tespit edilmiştir. Diğer yandan en yüksek SUVA değeri ise sırasıyla Terkos su örneklerinde $3.12 \mathrm{~L} / \mathrm{mg} . \mathrm{m}$, Büyükçekmece su örneklerinde $2.47 \mathrm{~L} / \mathrm{mg} . \mathrm{m}$ ve Ulutan Barajı su örneklerinde ise $2.13 \mathrm{~L} / \mathrm{mg} . \mathrm{m}$ olarak gözlenmiştir. SUVA değeri, yüzeysel sularda bulunan DOM'in yapısı ve klorlama sırasında meydana gelen THM gibi DYÜ'nin oluşumunun tahmininde kullanılan en önemli organik parametredir (Reckhow ve ark, 1990; Liang \& Singer, 2003). SUVA değeri $>3$ L/mg.m hidrofobik yapılı organik maddeleri, SUVA <3 L/mg.m ise hidrofilik yapıya sahip organik maddelerin varlığını göstermektedir (Edzwald ve ark, 1985). Bu sonuçlar en yüksek SUVA değerine sahip Terkos ham sularında bulunan DOM'in daha çok moleküler ağırlığı yüksek hidrofobik ve aromatik içeriği yüksek organik bileşiklerden meydana geldiğini, Büyükçekmece ve Ulutan Baraj suyunda mevcut DOM'in yapısında ise protein, aminoasit ve karbonhidratlar gibi hidrofilik organiklerin daha fazla miktarda bulunduğunu ortaya koymaktadır. Literatürde, SUVA değeri, yüksek moleküler ağırlığa sahip (hümik maddeler gibi) organik maddelerin hidrofobite ve aromatik içeriğinin tespitinde kullanılan önemli bir parametredir (Edzwald \& Van Benschoten, 1990; Yetis ve ark, 2007).

Bununla beraber her bir su kaynağından alınan su örneklerinin klorlanması sırasında en yüksek THMOP konsantrasyonu (350.04 $\mu \mathrm{g} / \mathrm{L})$ SUVA değeri en yüksek olan Terkos Göl suyu örneklerinde görülmüştür. Diğer yandan en düşük THMOP konsantrasyonu (204.56 $\mu \mathrm{g} / \mathrm{L}$ ) ise SUVA değeri en düşük olan Ulutan Baraj suyu örneklerinde görülmüştür. Bu sonuç aynı zamanda SUVA ile klorlama işlemi sırasında meydana gelen THM oluşumu arasında kuvvetli bir ilişki oluğunu göstermektedir. Başka bir deyişle, organik karbonu hidrofobik yapıda olan su kaynaklarının klorlanması sırasında hidrofilik organiklere göre daha yüksek miktarda THM meydana gelmektedir. Konu ile ilgili olarak Roccaro ve ark (2008) tarafından İtalya'da Ancipa ve Potamac yüzeysel su kaynaklarında yapılan benzer bir çalışmada SUVA >3'den büyük olan hidrofobik fraksiyonlu organiklerin klorlanması sonucunda yüksek miktarlarda THM oluşumu gözlenirken TTHM-SUVA arasında yüksek dereceli $\left(\mathrm{R}^{2}=0.83\right)$ olan lineer korelasyonlar bulunmuştur. 


\section{1. İçme Suyu kaynaklarında THM türlerinin dağılımı}

Şekil 1 de içme suyu kaynaklarının klorlanması sonucu 168 saatlik bekleme süresi sonucunda meydana gelen THM türlerinin dağılımı gösterilmiştir.
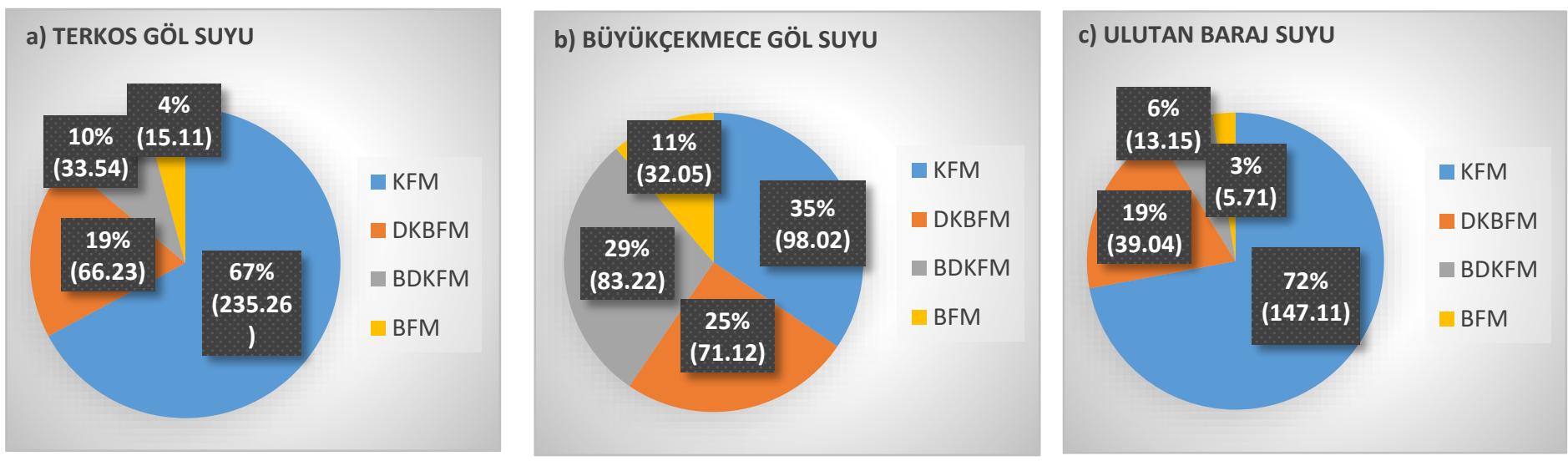

Şekil 1. THM türlerinin dağılımı (a) Terkos Gölü, (b) Büyükçekmece Gölü ve (c) Ulutan Barajı; (Klor dozu 10 mg/L, reaksiyon süresi 168 saat).

Buna göre Terkos, Büyükçekmece Göl suyu numuneleri ve Ulutan Barajı ham su örneklerinin klorlanması sonucunda meydana gelen THM türleri arasında en baskın türün KFM olduğu gözlenmiştir. Başka bir ifadeyle, Terkos Gölü ve Ulutan barajı ham su örneklerinde 168 saatlik bekleme süresi sonunda oluşan THMOP'nin büyük bir kısmını (toplam THM miktarının \%65 ve \%72'si) KFM oluştururken, diğer kısmını farklı oranlarda sırasıyla DKBFM, BDKFM ve BFM bileşikleri oluşturmaktadır. Bununla birlikte, maksimum KFM konsantrasyonu $235.26 \mu \mathrm{g} / \mathrm{L}$ ile klorlu Terkos Ham su örneklerinde ölçülürken, sırası ile en yüksek DKBFM (71,12 $\mu \mathrm{g} / \mathrm{L}), \mathrm{BDKFM}$ $(83.22 \mu \mathrm{g} / \mathrm{L})$ ve BFM $(32.05 \mu \mathrm{g} / \mathrm{L})$ konsantrasyonları klorlu Büyükçekmece ham su numunelerinde analiz edilmiştir. Bunun yanında en düşük bromürlü THM türleri konsantrasyonu, klorlu içme suyu kaynakları arasında $204 \mu \mathrm{g} / \mathrm{L}$ THMOP konsantrasyonuna sahip olan klorlu Ulutan Baraj su numunelerinde tespit edilmiştir.

Diğer yandan, klorlanmış Büyükçekmece ham su örneklerinde meydana gelen THM türleri klorlu Terkos ve Ulutan Baraj su örneklerinde görülen durumdan biraz farklılık göstermektedir (Şekil 1). Diğer içme suyu kaynaklarına oranla Büyükçekmece ham suyunda meydana gelen THMOP'nin büyük kısmını bromürlü türler oluşturmaktadır. KFM, THMOP’nin yaklaşık \%35'ini temsil ederken, geri kalan kısmı sırasıyla BDFKM (\%30), DBKFM (\%24) ve BFM (\%13)'den oluşturmaktadır. Literatürde çalışmamızın sonuçlarını destekleyen konu ile ilgili olarak, Uyak ve ark. (2007) ile Uyak ve ark. (2008) tarafından İstanbul da ki içme suyu kaynaklarında yapılan çalışmalarda, Büyükçekmece Göl suyunda bromürlü türlerin (diğer üç türe göre daha yüksek oranda kanser oluşturma potansiyeline sahip BDKFM bileşiği) daha fazla oranda tespit edildiği ortaya konmuştur. Bu sonucun en önemli nedenlerinden biri Marmara Denizine çok yakın olan Büyükçekmece Gölüne deniz suyu girişinin daha fazla olması dolayısıyla bromür seviyesinin (Çizelge 1) Terkos ve Ulutan Baraj suyundan daha yüksek tespit edilmesi olarak açıklanabilmektedir. Benzer sonuçlar daha önceki yapılan çalışmalarda da ortaya konulmuştur (Ozdemir ve ark, 2014). Diğer yandan bu çalışmanın diğer önemli bir sonucu ise $\mathrm{Br}^{-}$iyonun klorla oksidasyonu sonucunda meydana gelen hipobromonöz asitinin (HOBr), Hipokloröz asite ( $\left.\mathrm{HOCl}\right)$ kıyasla organik maddelerle daha hızlı ve aktif bir şekilde reaksiyona girdiğini göstermektedir. Bundan dolayı Br- konsantrasyonu yüksek olan Büyükçekmece Gölü ham sularının klorlanması sonucunda KFM'ye oranla daha fazla oranda bromürlü THM bileşikleri meydana geldiği gözlenmiştir.

\subsection{THM oluşumu üzerinde, pH, Klor dozu ve Klor temas süresinin etkileri}

Çözeltinin pH seviyesi klorlama süresince meydana gelen DYÜ’nin, tür ve miktarları üzerinde önemli etkisi bulunmaktadır (Ozdemir ve ark, 2014). Bu araştırmada, çalışılan üç içme suyu kaynağı için de; en yüksek THM miktarlarının en yüksek pH değerlerinde meydana geldiği gözlenmiştir. Şekil 2' de de görüldüğü üzere farklı pH değerlerinden klorlanmış Terkos, Büyükçekmece ve Ulutan Baraj suyu örneklerinde en yüksek KFM konsantrasyonun $\mathrm{pH} 4$ ve $\mathrm{pH} 6$ gibi asidik pH'lardan ziyade pH 9 gibi bazik pH değerlerinde meydana geldiği tespit edilmiştir. 
a) Terkos Göl Suyu

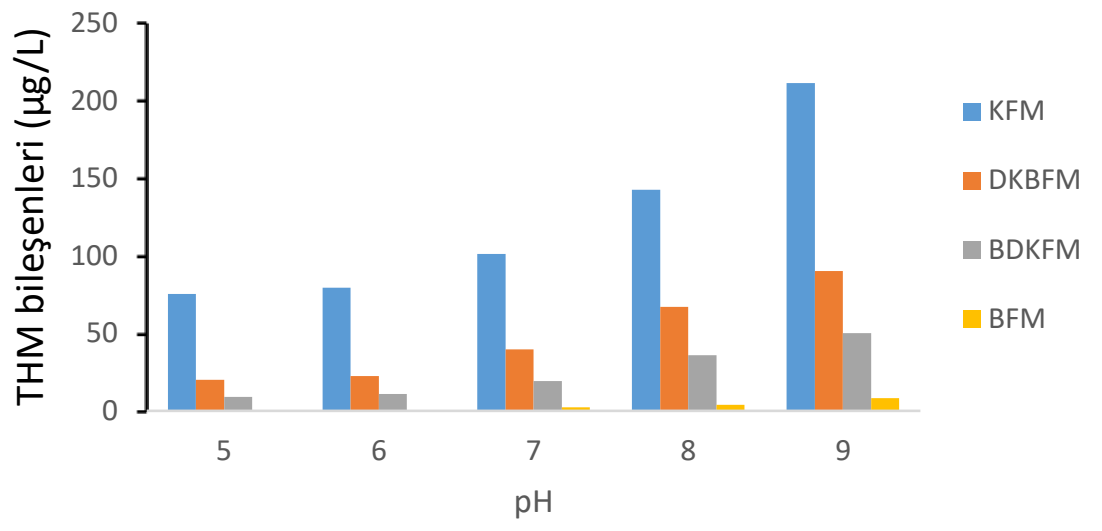

b) Büyükçekmece Göl Suyu

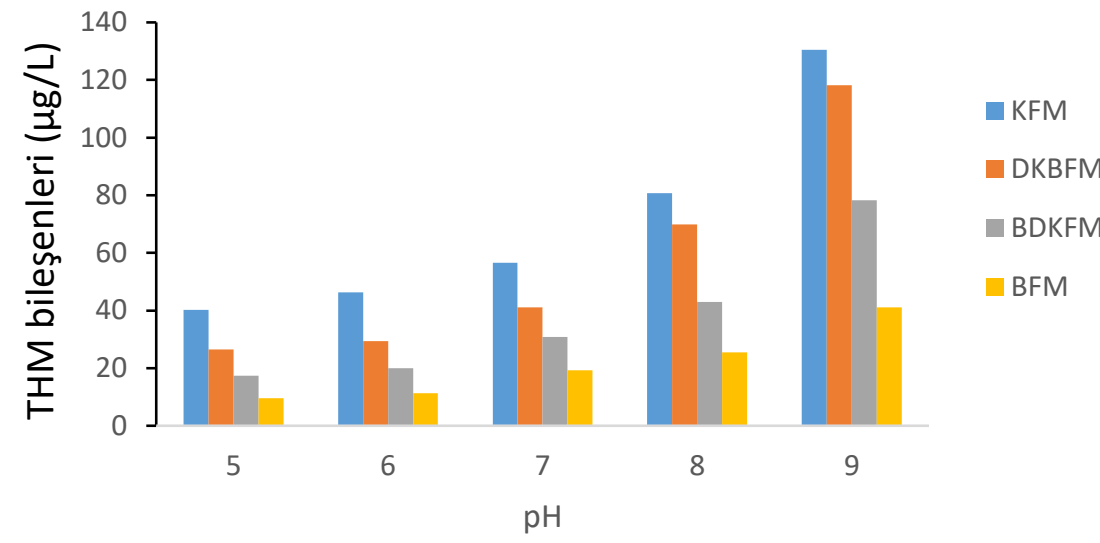

\section{c) Ulutan Baraj Suyu}

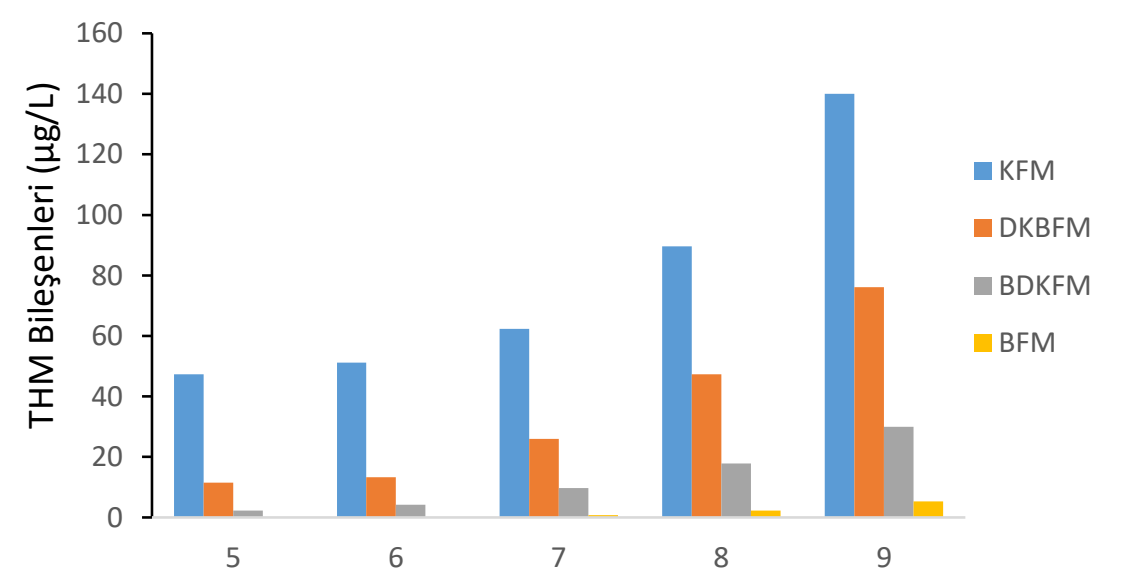

Şekil.2. Kloranlamış (a) Terkos Gölü suyu, (b) Büyükçekmece Gölü suyu, (c) Ulutan Baraj suyu numunelerinde THM bileşiklerinin pH ile değişimi (Klor dozu $10 \mathrm{mg} / \mathrm{L}$, reaksiyon süresi 168 saat).

Bununla birlikte, benzer eğilimin diğer THM türlerinde de bazik ortamda en yüksek konsantrasyonlara sahip olduğu gözlenmiştir. Başka bir ifadeyle, $\mathrm{pH}$ değeri yükseldikçe DKBFM, BDKFM ve BFM konsantrasyonlarının da belirli miktarlarda artı̧ olmaktadır. Bu sonuç, aynı zamanda Reckhow and Singer (1985) tarafindan yapılan çalışmalarda pH ve DYÜ oluşumu ile ilgili bir etkileşim mekanizması olduğunu göstermiştir (Şekil 3). 


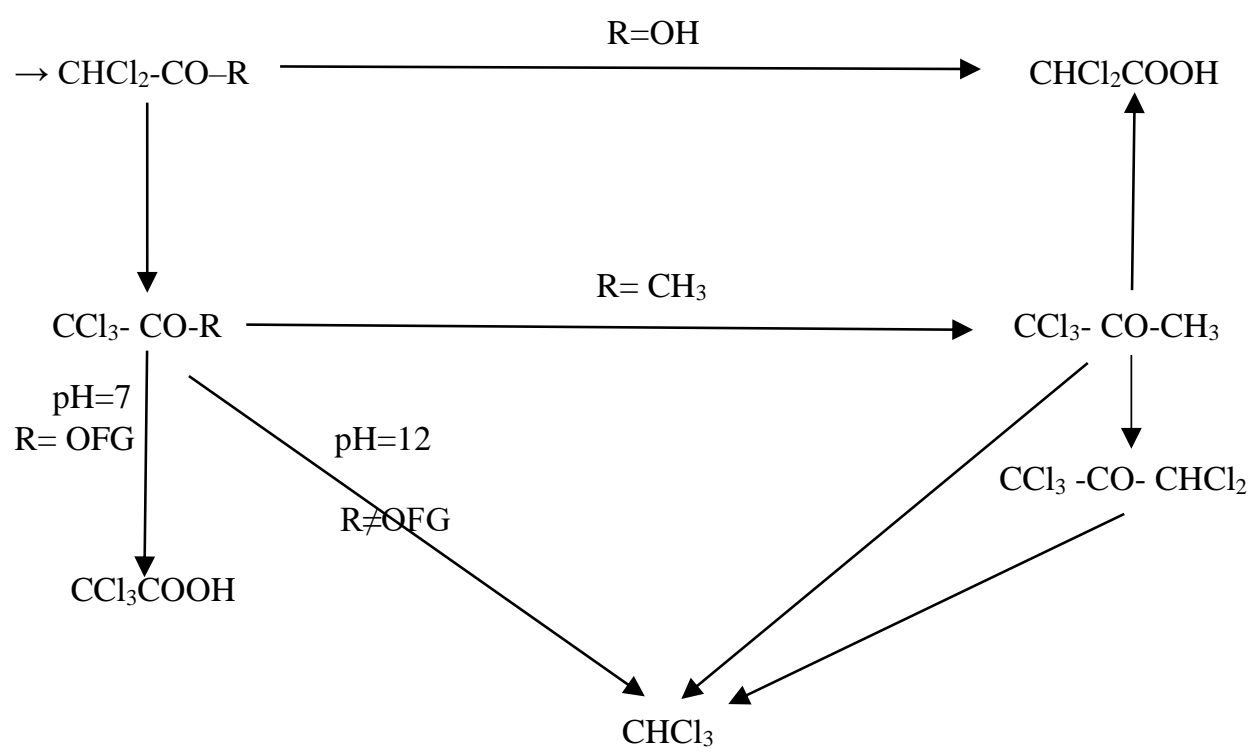

Şekil 3. Kloroform'un $\left(\mathrm{CHCl}_{3}\right)$ oluşumunu saglayan fulvik asitin klorlanma mekanziması. OFG: Oksitlenebilen fonsiyonel grup

Özellikle alkali koşullarda $\mathrm{OH}^{-}$iyonu ile organik karbon arasında meydana gelen hidroliz reaksiyonunun THM oluşumu üzerinde önemli bir etkisi olduğu ve bundan dolayı daha yüksek THM oluştuğu ortaya konulmuştur. Diğer yandan bu konu ile ilgili yapılan diğer araştırmalarda, alkali şartlarda DOM bileşikleri ile klor arasında meydana gelen baz-kataliz gibi yer değiştirme reaksiyonlarının DOMklor arasındaki oksidasyon reaksiyonlarından daha hızlı meydana geldiğini dolayısıyla özellikle pH 8 ve pH 9 gibi değerlerde daha yüksek miktarlarda KFM oluştuğunu göstermiştir (Reckhow ve ark, 1990; Liang \& ve Singer, 2003). Bu bulgular aynı zamanda bu çalışmada edilen sonuçları doğrulamaktadır.

Klor dozu ve reaksiyon süresi DYÜ oluşumu üzerinde önemli bir rol oynamaktadır (Ozdemir ve ark, 2014; Randtke ve ark, 1994). Şekil 4'de klorlanmış Terkos, Büyükçekmece ve Ulutan Barajı ham sularında meydana gelen TTHM konsantrasyonunun reaksiyon sürelerine göre değişimi görülmektedir.

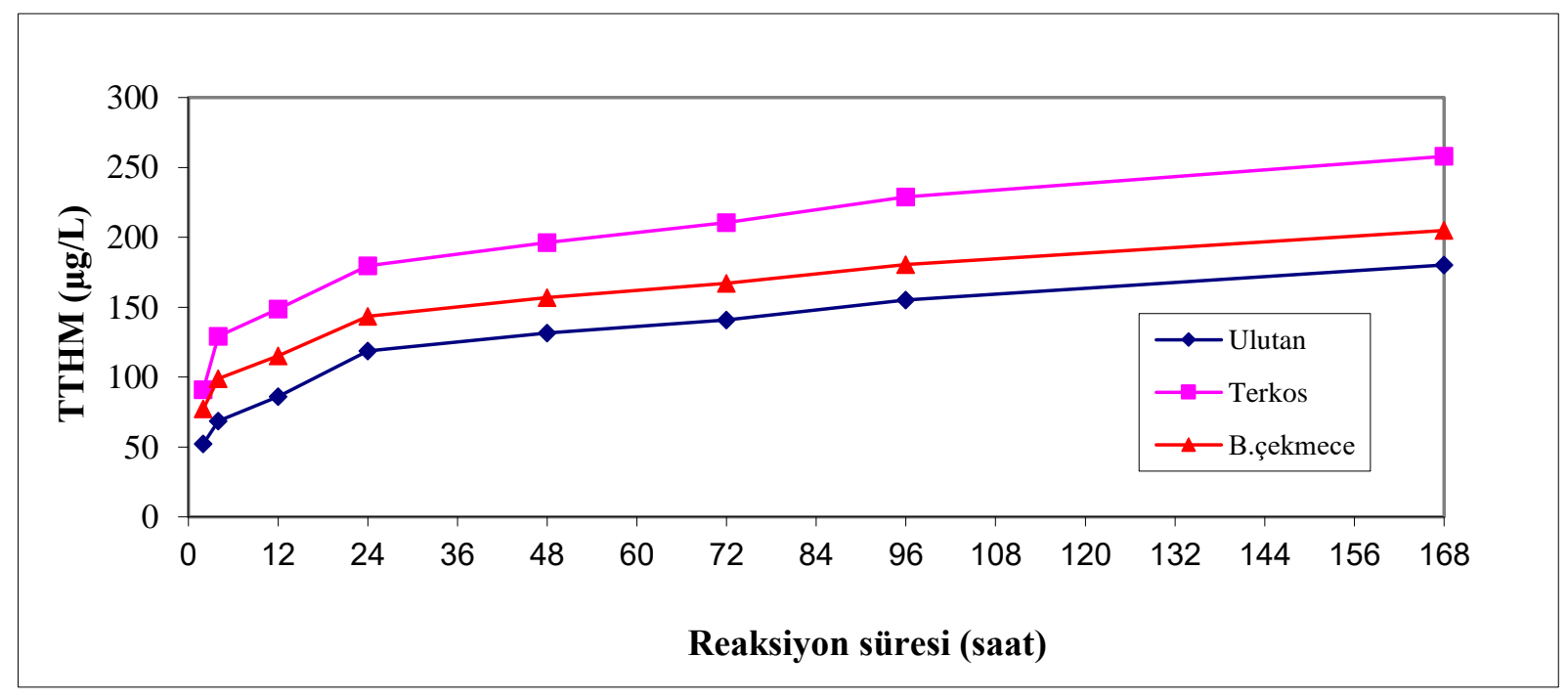

Şekil 4. Terkos, Büyükçekmece ve Ulutan Barajı ham su örneklerinde farklı reaksiyon sürelerinde oluşan TTHM konsantrasyonları $\left(\mathrm{pH} 7, \mathrm{Cl}_{2}=10 \mathrm{mg} / \mathrm{L}, \mathrm{T}=20^{\circ} \mathrm{C}\right.$ ve $\mathrm{t}=2-168$ saat $)$

Şekil 4'de klorlanmış su numunelerinde artan reaksiyon sürelerinde TTHM miktarlarının da belirgin bir artış gerçekleştiği gözlenmektedir. Klorlanmış her bir ham suda reaksiyon süresine bağlı olarak meydana gelen THM miktarlarının da değiştiği görülmüştür. 168 saatlik bekleme süresi içerisinde oluşan TTHM'in yaklaşı \% $\% 50^{\text {ee }}$ sinin 4 saatlik bir temas süresi sırasında oluştuğu belirlenmiştir. Klorlanmış Terkos Gölü suyunda 4 saatlik reaksiyon süresindeki $176.21 \mu \mathrm{g} / \mathrm{L}$ olarak bulunan bu değer 7 günlük TTHM miktarının $(350.04 \mu \mathrm{g} / \mathrm{L})$ yaklaşık \% 50 'eesini oluşturmaktadır. Diğer yandan 7 günlük bekleme süresinde oluşan TTHM'in miktar olarak yaklaşık \%90’1 96 saatlik bekleme süresi içinde ölçülen TTHM konsantrasyonu (313.02 $\mu \mathrm{g} / \mathrm{L})$ olmasına karşılık THM oluşum hızı ise 
European Journal of Science and Technology

sadece \%10’luk bir artış göstermektedir. Bu eğilim, Büyükçekmece Göl suları ile Ulutan Barajı su numunelerinde de tespit edilmiştir. Bu sonuç, klorlama prosesinin başlangıcında (0-4 saatlik temas süresi içinde) çok hızlı bir THM oluşumunun gerçekleştiğini daha sonra ise azalan bir hızla devam ettiğini ortaya koymaktadır. Benjamin ve diğ., (1997) tarafından yapılan çalışmalarda 7 günlük TTHM miktarının ilk 8 saatlik reaksiyon süresi içinde $\% 55$ ile $\% 60$ 'nın, meydana geldiği gözlenmiştir. Diğer yandan Çizelge 2'de farklı klor miktarlarında ve temas sürelerindeki TTHM derişimleri verilmiş̧ir.

Çizelge 2. Farklı klor dozlarında klorlanmış içme suyu kaynaklarında farklı reaksiyon süreleri sonunda oluşan TTHM derişimleri.

\begin{tabular}{|c|c|c|l|l|l|c|}
\hline \multirow{2}{*}{$\begin{array}{l}\text { Reaksiyon } \\
\text { süresi }\end{array}$} & \multicolumn{2}{l|}{ Ulutan Baraj1 Ham su } & \multicolumn{2}{l|}{ Terkos Gölü Ham su } & \multicolumn{2}{l|}{ Büyükçekmece Gölü Ham su } \\
\cline { 2 - 7 } & TTHM $(\mu \mathrm{g} / \mathrm{l})$ & $\mathrm{TTHM}(\mu \mathrm{g} / \mathrm{l})$ & $\mathrm{TTHM}(\mu \mathrm{g} / \mathrm{l})$ & $\mathrm{TTHM}(\mu \mathrm{g} / \mathrm{l})$ & $\mathrm{TTHM}(\mu \mathrm{g} / \mathrm{l})$ & $\mathrm{TTHM}(\mu \mathrm{g} / \mathrm{l})$ \\
\hline (Saat) & $\mathrm{Cl}_{2}=14.4 \mathrm{mg} / \mathrm{L}$ & $\mathrm{Cl}_{2}=5 \mathrm{mg} / \mathrm{L}$ & $\begin{array}{l}\mathrm{Tl} 2=12.15 \\
\mathrm{mg} / \mathrm{L}\end{array}$ & $\begin{array}{l}\mathrm{Cl}_{2}=5 \mathrm{mg} / \mathrm{L} \\
\mathrm{mg} / \mathrm{L}\end{array}$ & $\mathrm{Cl}_{2}=5 \mathrm{mg} / \mathrm{L}$ \\
\hline 2 & 62.25 & 41.80 & 160.11 & 73.03 & 123.39 & 52.88 \\
\hline 4 & 101.16 & 49.83 & 176.08 & 91.21 & 144.52 & 72.52 \\
\hline 12 & 119.26 & 58.29 & 219.64 & 111.02 & 170.24 & 84.34 \\
\hline 24 & 129.45 & 75.25 & 241.51 & 121.73 & 199.60 & 98.43 \\
\hline 48 & 142.89 & 81.47 & 263.22 & 137.23 & 221.77 & 107.42 \\
\hline 72 & 154.78 & 89.30 & 284.46 & 148.69 & 244.03 & 122.20 \\
\hline 96 & 174.21 & 93.98 & 313.02 & 161.26 & 266.41 & 135.09 \\
\hline 168 & 204.56 & 107.15 & 350.04 & 176.13 & 284.12 & 147.25 \\
\hline
\end{tabular}

Çizelge 2'de görüldüğü üzere, her bir içme suyu kaynağından alınan su numunelerine uygulanan klor dozu ve temas süresi artıkça buna paralel olarak oluşan TTHM miktarlarının da arttı̆̆ gözlenmiş̧tir. Çizelge 2'de, maksimum TTHM konstrasyonu, (14.4 mg/L klor dozunda ve 168 saatlik reaksiyon süreleri sonunda) Terkos Göl suyu numunelerinde gözlenmiştir. Ma ve ark. (2009) tarafindan gerçekleştirilen benzer bir çalışmada klor dozu $(2-10 \mathrm{mg} / \mathrm{L})$ ve reaksiyon zamanı (2-72 saat) arttıkça TTHM miktarlarının da arttığı tespit edilmiştir. Diğer yandan Çizelge-2 ve Şekil 4'e bakıldığında, her bir içme suyu kaynağının $\mathrm{TOK} / \mathrm{Cl}_{2}=3$ olacak şekilde klorlanması, 168 saatlik bekleme süresi sonunda su kaynağında oluşacak maksimum THM miktarını (THMOP) vermektedir. Çalışmamızda, 168 saatlik bekletme süresi sonunda DOM-klor arasında meydana gelen reaksiyonlar sonucunda klor miktarındaki değişimler Şekil 5'de gösterilmiştir.

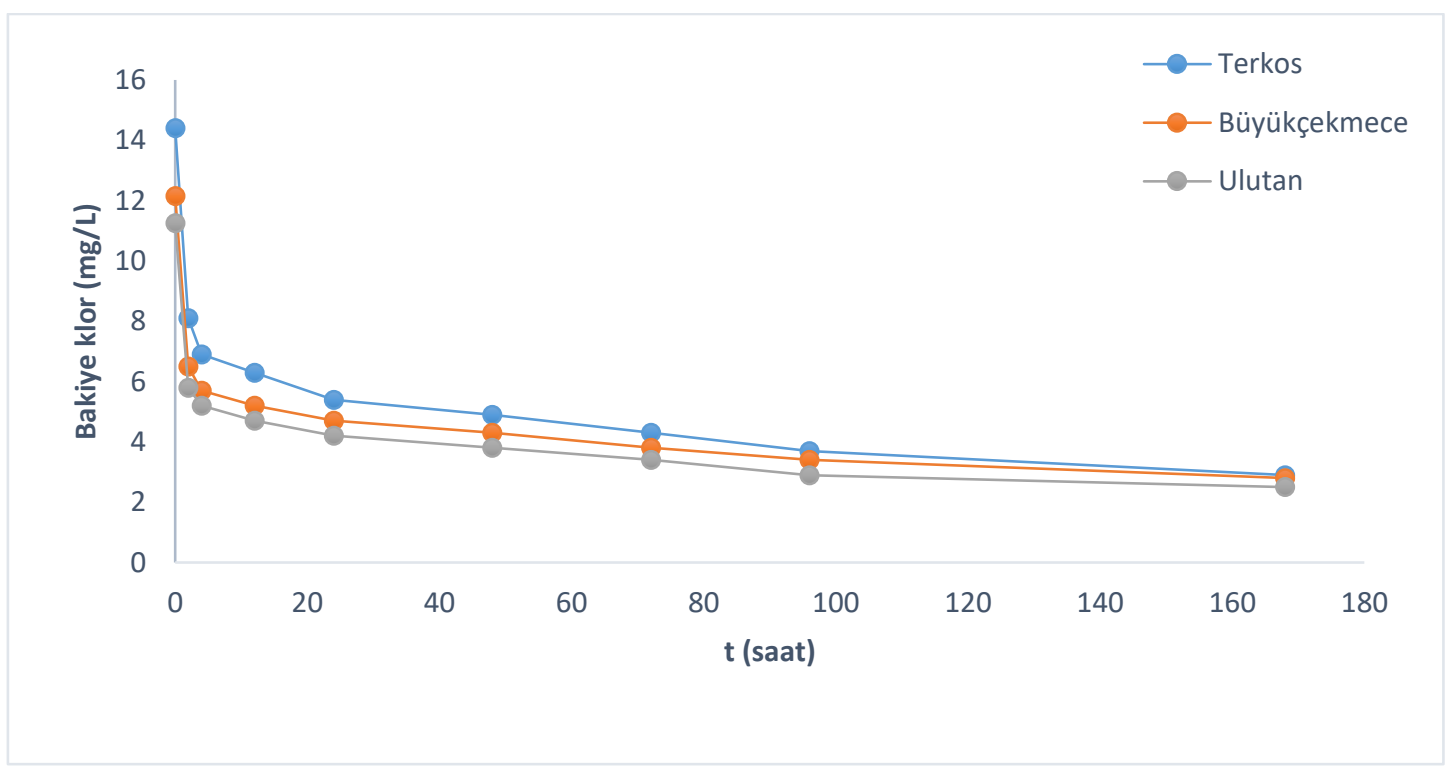

Şekil 5. Bakiye klor miktarının zamanla değişimi

Bu sonuç aynı zamanda belirtilen reaksiyon zamanlarında meydana gelen THM miktarı ile klor miktarındaki azalmalar arasında kuvvetli bir ilişki olduğunu göstermektedir. Şekil 5'e göre, ilk 2 saatlik reaksiyon süresi içerisinde klor miktarında hızlı bir düşüş meydana gelirken, reaksiyon sürelerinin sonuna doğru düşüş hızının yavaşladığı ve 168 saatlik reaksiyon sonunda ölçülen klor miktarında çok fazla bir değişim olmadığı görülmektedir. 


\section{Sonuç}

Bu çalışmada, Terkos Gölü, Büyükçekmece Gölü ve Ulutan Barajından alınan su numunelerinin klorlanması sonucu meydana gelen THMOP miktarı ve THM bileşiklerinin dağılımı üzerinde, içme suyu kaynağının içerdiği DOM'nin yapısı, bromür konsantrasyonu, $\mathrm{pH}$, klor dozu ve bekletme süresi gibi faktörlerin etkisi karşılaştırılarak incelenmiştir. Laboratuvar ortamında gerçekleştirilen deneysel çalışmalar sonucunda en yüksek THMOP konsantrasyonu $(350.04 \mu \mathrm{g} / \mathrm{L})$ ve SUVA değeri (3.12 L/mg.m) Terkos Gölü su örneklerinin klorlanması neticesinde elde edilmiştir. Her bir içme suyu kaynağının klorlanması sırasında THM bileşikleri arasında Kloroform’un (KFM) en yüksek oluşum oranına sahip olduğu görülmüştür. Buna karşılık, en fazla bromürlü THM türlerinin ise Büyükçekmece ham sularının klorlanması sonucunda meydana geldiği gözlenmiştir. Terkos, Büyükçekmece ve Ulutan Barajı su örneklerinde farklı pH'larda klorlanma yapılmış ve klorlama sonucunda en yüksek THM miktarlarının ise alkali pH değerlerinde $(\mathrm{pH}>7)$ meydana geldiği görülmüştür. Diğer taraftan, klorlanmış ham su örneklerinde 168 saatlik reaksiyon süresi sonunda oluşan TTHM miktarının yaklaşık \%50'sinin ilk 4 saatlik reaksiyon süresi sonunda meydana geldiği ve klor dozu arttıkça oluşan THM miktarının da doğrusal olarak arttığı tespit edilmiştir. Sonuç olarak, bu çalışma yüksek miktarlarda içme suyu üreten arıtma tesislerinin optimizasyonuna ve su kalite parametrelerine önemli bir katkı sağlayacaktır.

\section{Kaynakça}

Barret, S.E., Krasner, S.W., \& Amy, G.L. (2000). Natural organic material and disinfection byproducts: Characterization and Control in drinking water-An overview. ACS Symposium Series Vol. 761

Bellar T.A., Lichtenberg, J.J., \& Kroner, R.C. (1974). The occurrence of organohalides in chlorinated drinking waters. J Am Water Works Assoc, 66, 703-6.

Benjamin, M.M., Li, C.W., \& Korshin, G.V. (1997). The decrease of UV absorbance as a indicator of TOX formation. Water Res, 31(4), 946-949.

Cedergren, M.I., Selbing, A.J., Löfman, O., \& Bengt, A.J. (2002). Chlorination by products and nitrate in drinking water and risk for congenital cardiac defects. Environ Res, 89(2), 124-30.

Croue, J.P. (2004). Isolation of humic and non-humic NOM fractions: Structural characterization. Environ. Monit. Assess, 92 (1-3), $93-$ 207.

Croue', J.P., Korshin, G.V., \& Benjamin, M. (2000). Characterization of Natural Organic Matter in Drinking Water. Report no. 90780. miexde Am. Water Works Assoc. Research Foundation, USA

Dodds, L., King, W., Woolcott, C., \& Pole, J. (1999). Trihalomethanes in public water supplies and adverse birth outcomes. Epidemiology, 10(3), 233-41.

EC. (1998). EEC Council Directive 98/83/EC of 3 November 1998 on the quality of water intended for human consumption. Official Journal of the European Communities, L 330/32 5.12.98.

Edzwald, J.K., \& Van Benschoten, J.E. (1990). Aluminum coagulation of natural organic matter, In, Chemical water and wastewater treatment., p. 341-359, Eds. Hahn, H.H., Klute, R., Springer, Berlin.

Edzwald, J.K., Becker, W.C., \& Wattier, K.L. (1985). Surrogate parameters for monitoring organic matter and THM precursors. J Am Water Works Assoc, 77, 122-32.

Elshorbagy, W.E., Abu-Qadais, H., \& Elsheamy, M.K. (2000). Simulation of THM species in water distribution systems. Water Res, 34, 3431-9.

Gang, D. (2001). Modeling of THM and HAA formation in Missouri waters upon chlorination, PhD Thesis, Dissertation, the University of Missouri, Columbia,

USA.

Hwang, C.J., Sclimenti, M.J., \& Krasner, S.W. (2000). Disinfection by-products formation reactivities of natural organic matter fractions of a low humic water, American Chemical Society Series 761:173-187

Her, N., Amy, G., Chung, J., Yoon, J., \& Yoon, Y. (2008). Characterizing dissolved organic matter and evaluating associated nanofiltration membrane fouling, Chemosphere, 40, 402. Lefebvre, O., \& Moletta, R. (2006). Treatment of organic pollution in industrial saline wastewater: a literature review, Water Res, 40 ,

3671-3682.

Owen, D.M., Amy, G.L., Chowdhury, Z.K., Paode, R., Mccoy, G., \& Viscosil, K. (1995). NOM - characterization and treatability, J. Am. Water Works Ass, 87, 46-63. Vilge-Ritter, A., Masion, A., Boulange, T., Rybacki, D., \& Bottero, J.Y. (1999). Removal of natural organic matter by coagulationflocculation: a pyrolysis-GC-MS study. Environ. Sci. Technol, 33, 3027-3032.

Ivancev, V.T., Dalmacijam, B., Tamas, Z., \& Karlovic, E. (2002). The effect of different drinking water treatment processes on the rate of chloroform formation in the reactions of natural organic matter with hypochlorite. Water Res, 33, 3715-22.

Jacangelo, J.G., Demarco, J., Owen, D.M., \& Randtke, S.J. (1995). Selected processes for removing NOM - an overview, J. Am Water Works Ass, 87, 64-77

Kitis, M., Karanfil, T., Kilduff J. E., \& Wigton, A. (2001). The reactivity of natural organic matter to disinfection by-products formation and its relation to specific ultraviolet absorbance. Water Science and Technology, 43(2), 9-16.

Kitis, M., Karanfil, T., Kilduff J. E., \& Wigton, A. (2002). Probing reactivity of dissolved organic matter for disinfection by-product formation using XAD-8 resin adsorption and ultrafiltration fractionation, Water Res, 36(15), 3834-3848.

Lei, Y.D., \& Wania, F. (2004). Is rain or snow a more efficient scavenger of organic chemicals? Atmos Environ, 38, $3557-3571$.

Liang, L., \& Singer, P.C. (2003). Factors influencing the formation and relative distribution of haloacetic acids and trihalomethanes in drinking water. Environ Sci Technol, 37(13), 2920-8. 
Ma, J., Zhang, T., Lu, J., \& Chen, Z. (2009). Evaluation of disinfection byproducts formation during the chlorination and chloramination of dissolved organic matter fractions isolated from a filtered water, J Hazard. Materials. 162, 140-145.

Ozdemir, K., Toroz, I., \& Uyak, V. (2013). Assessment of trihalomethane formation in chlorinated raw waters with differential UV $\begin{array}{lllllll}\text { spectroscopy } & \text { approach. } & S c i & \text { World } & J, & 19, & 1-8 .\end{array}$ SM. (2005). AWWA, WEF Standard Methods for the Examination of Water and Waste Water, Washington, DC, USA, 21th edition.

Özdemir, K., Toröz, I., \& Uyak, V. (2014). Relationship Among Chlorine Dose, Reaction Time and Bromide Ions on Trihalomethane Formation in Drinking Water Sources in Istanbul, Turkey Asian J. Chem, 26 (20), 6935-9.

Pontius, F. (1993). D/DBP rule to set tight standards. J Am Water Works Assoc, 85, 22-30.

Randtke, S.C., Hoehn, R.C., Knocke, W.R., Dietrich, A.M., Long, B.W., Wang, N. (1994). A comprehensive assestment of DBP precusor removal by enhanced coagulation and softening, In: proceedings AWWA conference, 737, June 19-23.

Reckhow, D.A., Singer, P.C., \& Malcolm, R.L. (1990). Chlorination of humic materials: byproduct formation and chemical interpretations. Environ Sci Technol, 24, 1655-64.

Roccaro, P., Chang, H.S., Vagliasindi, G.A.F. \& Korshin, G.V. (2008). Differential absorbance study of effects of temperature on chlorine consumption and formation of disinfection by-products in chlorinated water, Water Res, 42, 1879-1888. Uyak, V., \& Toroz, I. (2007). Disinfection by-product precursors reduction by various coagulation techniques in Istanbul water

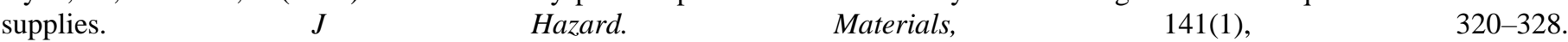
Uyak, V., Ozdemir, K., \& Toroz, I. (2008). Seasonal variations of disinfection by-product precursors profile and their removal through surface water treatment plants. Sci.Tot. Environ, 390(2-3), 417-424.

Rodriguez, M.J., \& Serodes, J.B. (2001). Spatial and temporal evolution of trihalomethanes in three water distribution systems. Water Res, 35, 1572-86.

Rook, J.J. (1974). Formation of haloforms during chlorination of naturals waters. Water Treat Exam, 23, 234-43.

Sadiq, R., \& Rodriguez, M.J. (2004). Disinfection by-products (DBPs) in drinking water and predictive models for their occurrence: a review, Water Res, 321, 21-46.

Sharp, E.L., Parsons, S.A., \& Jefferson, B. (2006). Seasonal variations in natural organic matter and its impact on coagulation in water treatment, Sci. Total $\quad$ Environ, $\quad 363, \quad 183-194$. Sharp, E.L., Parsons, S.A., \& Jefferson, B. (2006). The impact of seasonal variations in DOC arising from a moorland peat catchment on coagulation with iron and aluminum salts, Environ. Pollut, 140, 436-443.

Summers, R.S., \& Roberts, P.V. (1988). Activated carbon adsorption of humic substances: 1. Heterodisperse mixtures and desorption, J. Colloid Interf. Sci, 122, 367-381.

TSE-266. (2012). Regulation concerning water intended for human consumption and drinking water standarts. Turkish Ministry of Health, Official News Paper, 2005; 25730. Ankara

USEPA. (2003a). National primary drinking water regulations: stage 2 disinfectants and disinfection byproducts (D/DBP). Final rule, $68,159$.

USEPA. (2003b). Method 552.3. Determination of haloacetic acids and dalapon in drinking water by liquid-liquid microextraction, derivatization and gas chromatography with electron-capture detection,. Technical Support Center, Office of Groundwater and Drinking Water. Cincinnati, Ohio: US Environmental Protection Agency.

Uyak, V., Toroz, I., \& Meric, S. (2005). Monitoring and modeling of trihalomethanes (THM) for a water treatment plant in Istanbul, Desalination, 176, 91-101.

Yang, C.Y., Cheng, B.H., Tsai, S.S., Wu, T.N., Lin, M.C., Lin, K.C. (2000). Association between chlorination of drinking water and adverse pregnancy outcome in Taiwan. Environ Health Perspect, 108(8), 765-8.

Yetis, U., Dilek, F.B., Sahinkaya, E., Kaplan, S.S., \& Ates, N. (2007). Occurance of disinfection by products in low DOC surface waters in Turkey, J Hazard.Mat, 142, 526- 534.

Zou, H., Yang, S., \& Xu, O. (1997). Formation of POX and NPOX with chlorination of fulvic acid in water: emprical models. Water Res, 31(6), 1536- 1541. 